\title{
A ALFABETIZAÇÃO E OS INDIVÍDUOS ENVOLVIDOS COM/POR ELA
}

\author{
LITERACY AND PEOPLE INVOLVED IN/BY IT
}

\author{
Milka Helena Carrilho Slavez (UEMS/PG-PUC/SP)
}

\begin{abstract}
Resumo: Estudos na área das Ciências Sociais, realizados no doutorado subsidiam a pesquisa em andamento, têm possibilitado à pesquisadora repensar, agora sob o olhar da Sociologia, alguns aspectos do objeto de pesquisa que tem procurado entender no mestrado e no doutorado referente à alfabetização e os indivíduos envolvidos com/por ela. O presente trabalho propõe-se, inicialmente, a apresentar alguns conceitos elaborados por Elias (1994), esclarecedores acerca da função de modelação que a sociedade exerce nos indivíduos. Depois, pretende destacar aspectos desse referencial que podem ser relacionados com outros pressupostos teóricos que subsidiam a referida pesquisa para o doutorado, como os estudos sobre socialização primária e secundária, em Berger e Luckmann (2003) e socialização profissional docente, conforme Dubar (1997). Essa reflexão inicial aponta que a função exercida pelo professor alfabetizador e, por conseguinte, a sua identidade construída ao longo de sua trajetória pessoal e profissional, fazem parte de uma teia de relações.
\end{abstract}

Palavras-chaves: identidade profissional. socialização profissional. função de modelação.

Abstract: Researches in the Social Sciences field conducted by this researcher during the doctorate program has enabled her to reconsider, under the Sociology perspective, some aspects of the object of study she's been trying to unravel since her master's research concerning literacy and the people involved in and by it. This paper first presents a few concepts developed by Elias (1994) enlightening the shaping nature of society over the individuals. Second, it aims at highlighting aspects of such referential concepts that may be related to other theoretical assumptions involved in the main doctorate research theoretical framework, such as the studies about primary and secondary socialization, by Berger and Luckmann (2003), and teachers' professional and social development, according to Dubar (1997). This initial analysis shows that the function performed by the literacy teacher and, therefore, the identity built up over his/her personal and professional path, is part of a web of relations.

Keywords: professional identity. professional and social development. shaping nature.

Para abordar o tema do presente artigo será necessário inicialmente apresentar o indivíduo que o produz, levando em consideração sua trajetória e seu interesse pela alfabetização.

O início dessa caminhada se dá em 1985, em uma sala de pré-escola mantida por um convênio entre o extinto MOBRAL e a Prefeitura Municipal de Coroados - SP que funcionava em uma creche mantida por uma Associação Beneficente. Essa primeira atuação se deu concomitante com o quarto ano do magistério. Problemas encontrados na prática escolar somados às lacunas da formação inicial constituíram-se marcas dessa trajetória, e transformaram-se em impulsos a um processo constante de procura de explicações e busca de atualização, pois assim como afirma Geraldi (1997) "[...] ser professor é desatualizar-se".

Essa experiência, somada ao trabalho com formação de professores na área de Metodologia de Ensino de Língua Portuguesa e Prática de Ensino em cursos de Magistério gerou inquietações quanto à atuação do professor alfabetizador que levaram à continuação dessa formação. Desse modo, a questão da alfabetização tornou-se uma ideia fixa, como diria Machado de Assis, citado por Esteban e Zaccur (2002): "Deus te livre, caro leitor, de uma idéia fixa”. É que as idéias fixas, uma vez “[...] encarapitadas no trapézio da mente passam a exigir respostas, leituras, discussões, reflexões e, portanto, pesquisa...” (2002, p. 15). Assim, o interesse por esse assunto conduziu à

\begin{tabular}{|l|l|l|l|l|l|}
\hline Interfaces da Educ. & Paranaíba & v. 1 & n. 2 & p. 107-116 & 2010 \\
\hline
\end{tabular}


especialização na área de Alfabetização na Pontifícia Universidade Católica de Belo Horizonte.

O passo seguinte foi o ingresso no programa de Pós-graduação stricto-sensu da UNESP de Marília, na área da Educação. Nesse período, a atuação profissional ocorria no curso de formação de professores, no extinto Centro Específico de Formação e Aperfeiçoamento do Magistério - CEFAM - da cidade de Araçatuba-SP. Outras inquietações tornaram-se visíveis na supervisão dos estágios. Frequentemente eram presenciadas situações em que as crianças acabavam sendo ignoradas pelos professores, que davam mais atenção àqueles alunos que conseguiam acompanhar as atividades propostas. A suspeita de que esse desinteresse das crianças decorria de uma prática pedagógica desmotivadora e do trabalho efetuado com a leitura e a escrita distante da realidade provocou o interesse por desenvolver uma pesquisa que pudesse contribuir para compreensão das barreiras entre o ambiente escolar e a vida. Desse modo, a possibilidade de testar a introdução nas séries iniciais do ensino fundamental do uso de jornal como alternativa à utilização exclusiva do livro didático pareceu ser bastante apropriada a esse fim.

Como parte da pesquisa desenvolvida no mestrado foi realizada uma experimentação com crianças da $1^{\mathrm{a}}$ e $2^{\mathrm{a}}$ série do ensino fundamental de uma escola pública, na cidade de Araçatuba-SP. Os resultados apresentados corresponderam às expectativas, pois foi possível trabalhar com o jornal sem didatizá-lo, fazendo com que os alunos se envolvessem em situações prazerosas e significativas de leitura vinculadas a seu uso em nossa sociedade. Esse trabalho, sob a orientação da $\operatorname{Prof}^{a} \operatorname{Dr}^{a}$ Maria Alice de Oliveira Faria, resultou na dissertação de mestrado cujo título é: A imprensa na escola: o aprendizado da leitura do jornal como proposta metodológica, defendido na UNESP - Universidade Estadual Paulista - Campus de Marília - SP, em fevereiro de 2000.

Os caminhos que passaram a ser percorridos após esse período provocaram um intervalo em que houve um distanciamento do tema alfabetização, pois foi necessário o envolvimento com assuntos diversos demandados pelas disciplinas variadas oferecidas nos cursos das faculdades particulares que passaram a ser os locais de atuação profissional da pesquisadora.

Em meados de 2004 foi iniciada a carreira na universidade pública, após a aprovação em concurso público da Universidade Estadual de Mato Grosso do Sul UEMS, no curso de Pedagogia da Unidade de Paranaíba. Esse foi um passo importante dessa trajetória, pois finalmente a tão desejada estabilidade profissional começava a tornar-se realidade. A partir daí surgiu a necessidade de conhecer melhor a realidade daquele local para poder realizar um trabalho mais apropriado àquele contexto e assim desenvolver alguma atividade de extensão que pudesse contribuir com a melhoria da Educação Básica e, ao mesmo tempo, se tornar campo específico de pesquisa.

Essa oportunidade se consubstanciou em 2005 por meio do Projeto de Extensão: Programa de Formação Continuada para Docentes da Educação Básica do Bolsão SulMato-grossense. Por meio desse projeto de extensão com os professores e com as escolas públicas de Paranaíba - MS foi possível conhecer melhor a realidade educacional do local de atuação da recente etapa dessa trajetória. Mas, a participação nestes projetos despertou novas inquietações. Algumas questões tornaram-se ideias fixas e provocaram uma nova etapa dessa trajetória, agora no âmbito do doutorado, cursado no Programa de Estudos Pós-graduados em Educação: História, Política, Sociedade da Pontifícia Universidade Católica de São Paulo. 
A busca de respostas às questões que envolvem, por exemplo, os fatores que levam os professores a escolherem e permanecerem nas classes de alfabetização, bem como os saberes que eles adquirem ao longo de suas trajetórias ao exercerem esse ofício pareciam reunir as condições para propiciar uma compreensão sobre as necessidades da formação inicial que se apresentam na prática, fornecer elementos para melhor direcionar o trabalho nas disciplinas Metodologia de Alfabetização e Estágio Supervisionado, no curso de Pedagogia de Paranaíba - MS e, sobretudo, levar à investigação específica sobre processo de formação, trajetória e construção de identidade profissional docente de professores alfabetizadores.

$\mathrm{O}$ objeto de estudos Alfabetização esteve sempre presente nesta trajetória, porém as lentes usadas para sua compreensão foram as áreas de linguística e psicologia, ora com contribuições sobre especificidades próprias da língua materna, ora com conhecimentos a respeito de como os sujeitos aprendem a língua. Desse modo, justificase a pouca familiaridade com área das Ciências Sociais tanto pelo contato breve durante a formação inicial, quanto pela maior proximidade com outras áreas.

No Programa de Estudos Pós-graduados em Educação: História, Política e Sociedade oferecido pela Pontifícia Universidade Católica de São Paulo alguns estudos têm possibilitado à pesquisadora repensar, agora sob o olhar da Sociologia, alguns aspectos do objeto de pesquisa que tenho procurado entender no mestrado e no doutorado referente à alfabetização e aos indivíduos envolvidos com/por ela. O presente trabalho propõe-se, inicialmente, a apresentar alguns conceitos elaborados por Elias (1994), capazes de fazer entender a função de modelação que a sociedade exerce nos indivíduos.

A escolha por este autor se deve à consistência de suas ideias, apresentadas durante a disciplina oferecida no Programa citado, ministrada pela Prof ${ }^{\mathrm{a}}$ Alda Junqueira Marin denominada A escola como instituição social: estudos teóricos avançados II, cujo "[...] foco de estudo e análise são autores representativos das Ciências Sociais que auxiliam a compreensão da sociedade e, por decorrência, as instituições que a compõem, em especial a escola [...]".

Os estudos de Norbert Elias demonstram seu modo de encarar a questão da Cultura e merecem destaque, pois as análises feitas de sua obra tornam possível entender o indivíduo no coletivo e o lugar desse indivíduo nos grupos. Desse modo, esse coletivo que aparece de modo marcante na obra de Elias

[ ...] é voltado fundamentalmente para discutir a questão de valores, de condutas valoradas, condutas valorizadas e são esses elementos que dão unidade à vida societária a busca de entendimento do que é esse coletivo, do que é esse grupo no qual o indivíduo está, então a discussão para Elias particularmente, é ir em busca desses elementos que dão unidade à vida societária, que elementos são esses? Elias põe claramente que são principalmente valores que regem. (MARIN, 2009).

Outro aspecto da obra de Elias que deve ser ressaltado é o fato de ele considerar que para estudar as mudanças, os estudos de curta duração ou de conjuntura não conseguem verificar direcionamentos, não se consegue verificar direções para onde as mudanças levam, precisa-se de um tempo maior, por isso seus estudos são de longa duração. Elias analisa períodos marcados, sobretudo, por conflitos ou por alguma coisa que acontece e que faz com que haja algum tipo de modificação. Conforme esclarece Marin (2009), “[...] ele leva bem mais longe do que a História a configuração dos 
indivíduos, por isso ele pega a longa duração, são setecentos anos, e pega processos históricos, processos sociais que vão ser de longa duração".

Os estudos das obras de Elias $A$ sociedade dos indivíduos e $O$ processo civilizador possibilitaram olhar de modo diferente para o objeto de estudos, a alfabetização, mais especificamente os indivíduos envolvidos com/por ela. Assim, serão pinçados desses livros alguns conceitos que se acredita ser de grande valia para refletir sobre o tema dessa pesquisa.

Na obra $O$ processo civilizador será destacado o sentimento de vergonha. De acordo com Elias (1994), o sentimento de vergonha foi lentamente produzido e se tornou uma "segunda natureza", ou seja, algo que foi inculcado, como um autocontrole, um hábito que a pessoa faz mesmo quando está sozinha para não se sentir envergonhada. Elias esclarece que "O sentimento de vergonha é evidentemente uma função modelada segundo a estrutura social.” (ELIAS, 1994, p.143).

Este sentimento pode ser observado atualmente em indivíduos adultos analfabetos quando se encontram em situações nas quais são expostas suas dificuldades com a escrita em nossa sociedade letrada. Estes sujeitos se sentem como os únicos responsáveis por não terem sido alfabetizados. Mas de acordo com Barbosa (1992),

Se antes das mudanças revolucionárias que ocorrem no mundo ocidental no século XVIII, a leitura e a escrita eram privilégios de uma elite aristocrática, a partir de então passa a ser socialmente necessário que os usos da escrita se democratizem: a sociedade necessita de cidadãos, produtivos e alfabetizados. As práticas pedagógicas reformulam-se então, a fim de responder a essas novas necessidades sociais. (p. 45).

Assim, o sentimento de vergonha do sujeito analfabeto não existia há alguns séculos; ele foi sendo produzido lentamente numa sociedade que foi gradativamente exigindo sujeitos letrados em todas as classes sociais. As explicações apresentadas pelo autor sobre o processo como esse e outros sentimentos se estabelecem para a formação de indivíduos considerados "civilizados" amplia muito a compreensão da influência da sociedade no que tange à alfabetização.

Merece destaque, portanto, a função de modelação que a sociedade exerce sobre os indivíduos, apresentada por Elias (1994) ao afirmar que "“...] é sempre a sociedade como um todo, todo o conjunto de seres humanos, que exerce pressão sobre a nova geração, levando-a mais perfeitamente, ou menos, para seus fins." (p.145).

Outros aspectos a serem destacados dos estudos de Elias estão na obra $A$ sociedade dos individuos, pois nela o autor oferece esclarecimentos especialmente no que tange aos indivíduos, e nesta pesquisa em andamento sobre os percursos identitários dos professores alfabetizadores serão estudados os indivíduos envolvidos com/pela alfabetização. Desse modo, é de grande importância o que Elias (1994) explica sobre a identidade:

A identidade eu-nós anteriormente discutida é parte integrante do habitus social de uma pessoa e, como tal, está aberta à indivivualização. Essa identidade representa resposta à pergunta "Quem sou eu?" como ser social e individual. [...] Nessas sociedades, a resposta mais elementar à questão da identidade-eu do indivíduo, à pergunta “Quem sou eu?", é o nome-símbolo com que ele é registrado ao nascer. [...] E enquanto, de um lado, o nome dá a cada pessoa um símbolo de sua singularidade e uma resposta à pergunta sobre quem ela é aos seus próprios olhos, ele também serve de cartão de visita. 
Indica quem se é aos olhos dos outros.Também por esse prisma, vemos o quanto a existência da pessoa como ser individual é indissociável de sua existência como ser social. [...] Não há identidade-eu sem identidade-nós. Tudo o que varia é a ponderação dos termos na balança eu-nós, o padrão da relação eu-nós. (p.151152).

O conceito apresentado por Elias sobre a “(...) balança nós-eu, o qual indica que a relação da identidade-eu com a identidade-nós do indivíduo não se estabelece de uma vez por todas, mas está sujeita a transformações muito específicas". (1994, p.9). Essas afirmações possibilitam refletir sobre a constituição da identidade dos professores alfabetizadores, pois o modo como esses indivíduos se veem depende de como são vistos aos olhos dos outros.

Isso remete a outro conceito elaborado por Elias, o de interdependência, pois suscita que se pense na constituição da identidade de modo ampliado, considerando-se que

A ordem invisível dessa forma de vida em comum, que não pode ser diretamente percebida, oferece ao indivíduo uma gama mais ou menos restrita de funções e modos de comportamento possíveis. Por nascimento, ele está inserido num complexo funcional de estrutura bem definida; deve conformar-se a ele, moldar-se de acordo com ele e, talvez, desenvolver-se mais, com base nele. Até sua liberdade de escolha entre as funções preexistentes é bastante limitada. Depende largamente do ponto em que ele nasce e cresce nessa teia humana, das funções e da situação de seus pais e, em consonância com isso, da escolarização que recebe. (ELIAS, 1994, p.21).

A reflexão que se inicia nesse sentido é a de que a função que o professor alfabetizador exerce e, consequentemente, a identidade que se constrói ao longo de sua trajetória pessoal e profissional faz parte dessa teia de relações. Pois como esclarece Elias (1994), "Todas essas funções interdependentes, as de diretor de fábrica ou mecânico, dona-de-casa, amigo ou pai, são funções que uma pessoa exerce para outras, um indivíduo para outros indivíduos." (p. 23).

O apoio teórico de outros autores que se dedicam aos estudos sobre e socialização primária e secundária, como Berger e Luckmann (2003) e socialização profissional docente, como Dubar (1997), também oferecem elementos para a compreensão a respeito dos indivíduos envolvidos com/pela alfabetização. Isso justifica a escolha destes autores, que foram estudados na disciplina Processos de Formação de Professores e Estatuto Profissional do Magistério, ministrada pela Prof ${ }^{\mathrm{a}}$ Luciana Maria Giovanni, do Programa de Estudos Pós-graduados em Educação: História, Política e Sociedade da Pontifícia Universidade Católica de São Paulo.

Para Berger e Luckmann (2003), a sociedade é constituída por uma realidade ao mesmo tempo objetiva e subjetiva, deve ser entendida num processo dialético composto de três momentos: exteriorização, objetivação e interiorização, que ocorrem simultaneamente.

A interiorização resulta da compreensão do mundo no qual os outros vivem e da apropriação desse mundo pelo indivíduo. Há uma identificação mútua entre os indivíduos que vivem no mesmo mundo e que participam reciprocamente do ser do outro. Isso se realiza pelo processo de socialização definido por Berger e Luckmann como "[...] a ampla e consistente introdução de um indivíduo no mundo objetivo de uma sociedade ou de um setor dela." (p.175). 
O primeiro contato do indivíduo com a sociedade ocorre na infância e é denominado pelos autores de socialização primária; ocorre intermediada pelos "outros significativos" $"$ que lhe apresentam ao mundo, a realidade objetiva, segundo suas próprias definições. O mundo social é mediado pelos "outros significativos" que o entendem segundo sua posição na estrutura social e também de acordo com sua própria biografia; esses são "filtros" por meio dos quais o mundo é apreendido.

$\mathrm{O}$ aspecto emocional é fundamental na socialização primária, pois facilita o processo de aprendizado. A identificação emocional do indivíduo com os "outros significativos" irá determinar a interiorização. Desse modo, a identidade da criança é subjetivamente apropriada e objetivamente atribuída, num processo dialético em que ocorre a identificação pelos outros e a auto-identificação. A identidade recebida pela criança, quem ela é, irá determinar o lugar que ocupa no mundo. Na socialização primária os papéis e atitudes absorvidos pela criança por meio dos outros significativos são progressivamente abstraídos para o outro generalizado, isto é, para a sociedade.

Não há escolhas na socialização primária, a criança se identifica com os outros significativos automaticamente. Também não se cogita a possibilidade de outros mundos, o mundo interiorizado por ela é único, por isso é mais firmemente delineado em sua consciência.

Quanto aos conteúdos que o indivíduo precisa para aprender e as sequências desse aprendizado, Berger e Luckmann (2003) reconhecem que os aspectos biológicos precisam ser considerados no que se refere à idade em que a criança se encontra e o que pode aprender. Contudo, afirmam que também devem ser observadas as variações de cada sociedade, pois aquilo que pode ser considerado como infância em uma realidade social, em outra já será tido como fase adulta. Portanto, na socialização primária é extremamente importante para a inserção do indivíduo na sociedade, pois é a primeira e a mais marcante; mas a socialização nunca está terminada, a sociedade, a identidade e a realidade serão constantemente interiorizadas.

Segundo os autores, as novas interiorizações, chamadas de socializações secundárias, são definidas como a "[...] aquisição do conhecimento de funções específicas, funções direta ou indiretamente com raízes na divisão do trabalho [...] e a concomitante distribuição social do conhecimento." (p.185).

Diferente do que ocorre na socialização primária, quando o "mundo básico" é adquirido, na socialização secundária constituem-se os "submundos", neles são interiorizadas realidades parciais, compostas por elementos normativos, afetivos e cognoscitivos. Sua interiorização requer aquilo que os autores denominam de "aparelho legitimador", muitas vezes acompanhado por símbolos rituais ou materiais, porque nem sempre a tarefa a ser realizada facilita a identificação, assim, ela é legitimada por meio de ritos.

O principal problema da socialização secundária é a interiorização de novos conteúdos sobrepondo-os à realidade já interiorizada; nem sempre isso ocorre de modo coerente e sem conflitos.

Os aspectos biológicos são menos determinantes para o aprendizado na socialização secundária, sua sequência depende mais da estrutura do conhecimento a ser adquirido. Porém, a maneira como são estabelecidas estas sequências poderá servir a interesses ideológicos ou para reforçar o prestígio da função a ser apreendida. Diferente

\footnotetext{
${ }^{1}$ Para Berger e Luckmann (2003) "Todo indivíduo nasceu em uma estrutura social objetiva, dentro da qual encontra os outros significativos que se encarregam de sua socialização.” (p.175)
} 
da socialização primária, quando a identificação é acompanhada de emoção, na socialização secundária o que predomina é o formalismo e o anonimato das relações. Contudo, é muito mais difícil desintegrar a realidade interiorizada na primeira do que na segunda. Por isso os conhecimentos a serem ensinados precisam ser reforçados, eles devem parecer vívidos, importantes e interessantes, ou seja, aproximarem-se do que já é o "mundo doméstico" da criança.

Como existe a divisão do trabalho e a consequente distribuição social do conhecimento, a socialização secundária ocorrerá de modo diferenciado, dependendo das exigências para exercer as tarefas e podendo até mesmo requerer mais racionalidade e menos emoção ou vice-versa. Assim, interessa a esta pesquisa investigar em que consiste a socialização de professores alfabetizadores.

Esclarecido como ocorrem as duas formas de socialização, a primária e a secundária, os autores questionaram: como são conservadas ou transformadas as realidades interiorizadas nessas socializações? Para responder a esse questionamento, Berger e Luckmann (2003) enfocam o processo pelo qual a realidade é apreendida na consciência individual.

Para Berger e Luckmann (2003) existem dois tipos de conservação da realidade interiorizada, um denominado "conservação rotineira", que ocorre em situações do cotidiano, e é mantida pelas rotinas; o outro chamado "conservação crítica", nela a conservação da realidade ocorre em situações de crise.

A realidade interiorizada é mantida na consciência por processos sociais, que conservam o princípio de que a realidade subjetiva e a objetiva têm uma relação socialmente definida. Nessa relação, tanto os outros significativos como o outros menos importantes, que são encontrados pelo indivíduo no seu cotidiano, servem para reafirmar a realidade objetiva, mesmo que isso ocorra numa situação pouco significativa.

Os contatos casuais do dia-a-dia com outros menos importantes servem para confirmar progressivamente a identidade, mas ela precisa ser confirmada, explicitamente carregada de emoção e deve ser atribuída pelos outros significantes, por isso eles são tão importantes; são os principais agentes na confirmação da realidade subjetiva.

Diante disso, interessa investigar: quem foram e quem são os outros significativos para a confirmação da identidade dos professores alfabetizadores? Nesse tratado de sociologia, os autores apontam a conversa como o veículo mais importante da conservação da realidade. Neste sentido, afirmam: "[...] Pode-se considerar a vida cotidiana do indivíduo em termos do funcionamento de um aparelho de conversa, que continuamente mantém, modifica e reconstrói sua realidade subjetiva." (BERGER e LUCKMANN, 2003, p. 202).

Numa conversa, a troca de palavras entre dois ou mais indivíduos, tem como pano de fundo o mundo conhecido por eles como verdadeiro, desse modo, ela irá confirmar a realidade subjetiva desse mundo. Assim, até mesmo a maioria das conversas casuais servirá para confirmar a realidade subjetiva.

O indivíduo ao se expressar por meio da conversa poderá ter reforçada a realidade subjetiva de uma coisa já apreendida. Do mesmo modo, aquela realidade subjetiva sobre a qual ele nunca fala, torna-se frágil. Isso revela, segundo os autores, que "[...] a força geradora da realidade, possuída pela conversa, é dada já no fato da objetivação lingüística." (p.204).

Desse modo, o uso da mesma língua para "objetivar a experiência biográfica" entre os indivíduos faz deles outros mantenedores da realidade. Para que a realidade 
subjetiva seja efetivamente mantida, o aparelho de conversa deve ser contínuo e coerente. Os autores afirmam que a manutenção da auto-identificação dos indivíduos se dará na convivência em um meio que confirme essa identidade, com um grupo de referência. $\mathrm{O}$ contato social com esse grupo irá reavivar as lembranças e conservar sua contínua auto-identificação.

Partindo dessas considerações, pretende-se identificar: quem são os interlocutores dos professores alfabetizadores? Com quem eles conversam para objetivar suas dúvidas e saberes relacionados à alfabetização?

Percebe-se diante do que foi exposto que a realidade subjetiva pode ser transformada, pois o simples fato do indivíduo estar em sociedade já possibilita esse processo de modificação que exigirá processos de "ressocialização". Para que isso aconteça será necessária uma base social, uma "estrutura de plausibilidade"; nela o indivíduo irá se identificar com outros significativos, assim a transformação radical da realidade subjetiva e da identidade será possível.

No entanto, a ressocialização não é simples, ela exige uma reconstrução da realidade, novamente, mesmo que para isso o indivíduo seja levado a uma ruptura biográfica, fazendo uma reinterpretação dos acontecimentos do passado para harmonizá-los com a realidade presente.

Portanto, a interiorização da realidade subjetiva se inicia com a socialização primária, mas considerando-se que a socialização é inacabada, ela continuará a ocorrer na socialização secundária e até mesmo na ressocialização. Contudo, os outros significativos são determinantes para qualquer uma das socializações em questão. Assim, poderá ocorrer constantemente a interiorização da sociedade, da identidade e da realidade.

Dubar (1997) também destaca a importância do outro em sua definição de identidade, para ele são inseparáveis a identidade para si e identidade para o outro, pois "[...] eu só sei quem eu sou através do olhar do Outro" (p.104). Porém, isso provoca incertezas, pois o Eu constrói e reconstrói sua identidade na impressão que tem sobre o que os outros pensam sobre ele. Mas nunca se terá a certeza de que isso é a realidade.

Também é possível ao indivíduo recusar a identificação atribuída pelo outro. De todo modo, serão utilizadas "categorias socialmente disponíveis", como por exemplo, denominações oficiais, étnicas ou profissionais. Assim, o tipo de homem que se é, ou seja, a identidade para o outro, é chamada, segundo Dubar, de "atos de atribuição". Ele denomina "atos de pertença" a identidade para si, isto é, o modelo de homem que se quer ser. Entretanto, somente por meio da atividade com outros, as identificações que o indivíduo recebe se justificarão e mostrarão seus motivos; nessas situações ele poderá recusar ou aceitar a maneira como é identificado.

A teoria sociológica apresentada por Dubar (1997) tem como ponto central a articulação entre dois processos identitários heterogêneos. Primeiramente aquele que trata da atribuição da identidade e decorre da interação das instituições e agentes com o indivíduo, deve ser analisado dentro dos "sistemas de ação" no qual o indivíduo está inserido; neles são legitimadas categorias que são impostas coletivamente e que levam à etiquetagem. Assim, empresta-se uma identidade social "virtual" a uma pessoa.

$\mathrm{O}$ outro processo refere-se à incorporação da identidade pelos próprios indivíduos, sua análise deve ser feita considerando-se as "trajetórias sociais" por meio das quais os indivíduos constroem a "identidade para si”, também chamadas de identidades sociais "reais". Neste caso, a legitimidade irá depender daquilo que tem "subjetivamente" importância para o indivíduo. Desse modo, a identidade social é 
marcada pela dualidade; ela resulta da articulação entre a identidade virtual e identidade real, numa configuração identitária estável, mas sempre evolutiva.

Apesar da heterogeneidade desses dois processos, biográfico (identidade para si) e relacional (identidade para outro), ambos utilizam "esquemas de tipificação" que pressupõe a existência "[...] de um número limitado de modelos socialmente significativos para realizar combinações coerentes de identificações fragmentárias" (ERIKSON apud DUBAR, 1997, p.110). Temos, portanto, categorias que servem tanto para identificar os outros como a nós mesmos; elas variam em relação aos espaços sociais e ao tempo histórico e biográfico onde se desenvolveram as trajetórias sociais.

Dubar (1997) esclarece que embora as categorias possam sofrer variações, os campos escolar e profissional adquiriram grande legitimidade a partir dos anos 1980, porque "trabalho, emprego e formação" são considerados aspectos pertinentes das identificações sociais dos próprios indivíduos. Ele destaca que a partir do período mencionado se tornou cada vez mais estreita a relação emprego-formação, mas adverte que as identidades sociais não devem ser reduzidas a essas duas categorias.

Convém destacar que antes de ocorrer a identificação nas relações profissionais ou nas escolares, assim como Berger e Luckman (2003), Dubar (1997) atribui primordial importância à primeira identidade adquirida na infância, na relação da criança com a mãe ou quem a substitui. Mas a primeira identidade social é experimentada na escola por meio das categorizações dos outros, que no caso são os colegas e professores.

Como explica Dubar (1997, p.113), o processo identitário biográfico, ou seja, o aprendizado que nos leva a sermos quem somos é marcado pela dualidade

[...] entre a nossa identidade para o outro conferida e a nossa identidade para si construída, mas também entre nossa identidade social herdada e a nossa identidade escolar visada, nasce um campo de possibilidades, onde se desenrolam desde a infância à adolescência e ao longo de toda vida todas as nossas estratégias identitárias.

A construção da identidade autônoma, que ocorre quando o indivíduo sai do sistema escolar e se depara com o mercado de trabalho é, atualmente, um momento crucial, pois a realidade é marcada por fatores como desemprego, mudanças organizacionais, aceleração da modernização tecnológica e falta de estabilidade no emprego. No confronto com esta realidade a primeira "identidade profissional para si" é construída, mas ela não é definitiva e será frequentemente confrontada com outras transformações do mercado de trabalho e terá que sofrer ajustes constantes, por isso é marcada pela incerteza.

Diante deste quadro inconstante, para a pesquisa aqui proposta é possível levantar-se o seguinte questionamento: o processo de atribuição/escolha das classes nas escolas possibilita projeções para o futuro, de modo que a instabilidade não seja uma ameaça para a construção da "identidade profissional para si" dos professores alfabetizadores?

Ainda com apoio nos estudos apresentados por Dubar (1997), é possível observar que, por meio das relações de trabalho ou da participação nas associações profissionais, se realiza nos indivíduos a construção biográfica de uma identidade profissional, num movimento denominado processo identitário relacional. Mas o autor apresenta a seguinte hipótese: “[...] o investimento privilegiado num espaço de reconhecimento identitário está intimamente dependente da natureza das relações de 
poder neste espaço, do lugar que o indivíduo ocupa e do seu grupo de pertença." (p.117).

Portanto, segundo Dubar (1997), a articulação dos dois processos identitários - o biográfico e o relacional - revela a projeção do espaço-tempo identitário, pois uma geração constrói sua identidade social a partir das categorias herdadas das gerações anteriores e também por meio das estratégias identitárias desenvolvidas nos espaços das instituições em que os indivíduos percorrem em suas trajetórias sociais.

Essa observação instiga a necessidade de identificar quais elementos dos dois processos identitários - o biográfico e o relacional - foram determinantes para a constituição da identidade social dos professores alfabetizadores.

Ainda será necessário continuar o movimento de reflexão iniciado no presente trabalho, mas os estudos de Elias (1994) possibilitaram entender a modelação a que os indivíduos são submetidos na sociedade. Também foram esclarecedoras suas explicações sobre a constituição da identidade, pois a existência do indivíduo como ser único é inseparável de sua existência como ser social. O conceito de interdependência provoca reflexões quanto à teia de relações nas quais os indivíduos envolvidos com/pela alfabetização estiveram enredados em suas trajetórias.

Os questionamentos destacados dos estudos sobre socialização primária e secundária, de Berger e Luckmann (2003), e socialização profissional docente, de Dubar (1997), também oferecem elementos para a compreensão a respeito da socialização dos indivíduos envolvidos com/pela alfabetização e necessitam de respostas que estão sendo buscadas na pesquisa que se encontra em andamento.

\section{REFERÊNCIAS BIBLIOGRÁFICAS}

BARBOSA, José Juvêncio. 1994. Alfabetização e Leitura. São Paulo: Cortez.

BERGER, Peter L.; LUCKMANN, Thomas. 2003. A construção social da realidade: tratado de sociologia do conhecimento. Tradução de Floriano de Souza Fernandes. Petrópolis, Vozes. p. 173-241.

ELIAS. Norbert. O processo civilizador. Rio de janeiro: Zahar, 1994. v. I. A sociedade dos indivíduos. Rio de janeiro: Zahar.

ESTEBAN, M. T.; ZACCUR, E. 2002. A pesquisa como eixo de formação docente. Rio de Janeiro: DP\&A.

GERALDI, Jõao W. Portos de passagem. 4. ed. São Paulo: Martins Fontes, 1997.

MARIN, Alda Junqueira. Síntese das principais idéias de Norbert Elias. Aula ministrada no Programa de Estudos Pós-graduados em Educação: História, Política e Sociedade da Pontifícia Universidade Católica de São Paulo, 2009. 